ORIGINAL ARTICLE

\title{
IPSS-independent prognostic value of plasma CXCL10, IL-7 and IL-6 levels in myelodysplastic syndromes
}

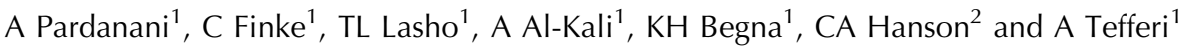 \\ ${ }^{1}$ Department of Medicine, Division of Hematology, Mayo Clinic, Rochester, MN, USA and ${ }^{2}$ Department of Laboratory Medicine, \\ Division of Hematopathology, Mayo Clinic, Rochester, MN, USA
}

\begin{abstract}
Recent studies suggest a powerful prognostic value for plasma cytokine levels in primary myelofibrosis (interleukin (IL)-2R, IL-8, IL-12, IL-15 and C-X-C motif chemokine 10 (CXCL10)) and large-cell lymphoma (IL-2R, IL-8, IL-10, IL-12, CXCL9 and CXCL10). To examine the possibility of a similar phenomenon in myelodysplastic syndromes (MDS), we used multiplex enzyme-linked immunosorbent assay to measure $\mathbf{3 0}$ plasma cytokines in 78 patients with primary MDS. Compared with normal controls $(n=35)$, the levels of 19 cytokines were significantly altered. Multivariable analysis identified increased levels of CXCL10 $(P<0.01)$, IL-7 $(P=0.02)$ and IL-6 $(P=0.07)$ as predictors of shortened survival; the survival association remained significant when the Cox model was adjusted for the International Prognostic Scoring System, age, transfusionneed or thrombocytopenia. MDS patients with normal plasma levels of CXCL10, IL-7 and IL-6 lived significantly longer (median survival 76 months) than those with elevated levels of at least one of the three cytokines (median survival 25 months) $(P<0.01)$. Increased levels of IL- 6 were associated with inferior leukemia-free survival, independent of other prognostic factors $(P=0.01)$. Comparison of plasma cytokines between MDS $(n=78)$ and primary myelofibrosis $(n=127)$ revealed a significantly different pattern of abnormalities. These observations reinforce the concept of distinct and prognostically relevant plasma cytokine signatures in hematological malignancies.
\end{abstract}

Leukemia (2012) 26, 693-699; doi:10.1038/leu.2011.251;

published online 13 September 2011

Keywords: MDS; cytokines; prognosis; interleukin; IP-10

\section{Introduction}

Aberrant cytokine expression accompanies both lymphoid and myeloid malignancies and is believed to contribute to disease phenotype and outcome. Recent studies in diffuse large B-cell lymphoma and primary myelofibrosis (PMF) have provided proof-of-concept in this regard by demonstrating phenotypic correlates and a powerful prognostic value for plasma levels of certain cytokines; circulating levels of interleukin (IL)-2R, interleukin (IL)-8, IL-12, IL-15 and C-X-C motif chemokine 10 (CXCL10) in PMF and IL-2R, IL-8, IL-10, IL-12, CXCL9 and CXCL10 in diffuse large B-cell lymphoma were independently associated with worse survival. ${ }^{1,2}$ In addition, in PMF, JAK2V617F-positive patients, compared to their mutationnegative counterparts, were more likely to display higher plasma levels of IL-1RA, IL-2R, IL-6, IL-12, hepatocyte growth factor (HGF), CXCL10 and monokine induced by interferon

Correspondence: Dr A Pardanani, Department of Medicine, Division of Hematology, Mayo Clinic, 200 First Street SW, Rochester, MN 55905, USA.

E-mail: pardanani.animesh@mayo.edu

Received 29 June 2011; accepted 4 August 2011; published online 13 September 2011
(IFN)- $\gamma$; other phenotypic correlates included increased levels of (i) IL-6 and IL-8 with constitutional symptoms, (ii) HGF with marked splenomegaly, (iii) IL-2R, IL-8, IL-10, macrophage inflammatory protein (MIP)- $1 \alpha$ and monocyte chemotactic protein-1 with red cell transfusion dependency, (iv) IL-2R, HGF and CXCL10 with leukocytosis and (v) CXCL10 with thrombocytopenia. Furthermore, a recent report suggested that anemia response to pomalidomide treatment in PMF was predicted by lower levels of circulating monocyte chemotactic protein-1, IL-2R, IL-15 and IL-8. ${ }^{3}$

The above-mentioned observations in PMF strongly suggest that specific cytokines contribute to specific disease symptoms and poor survival, and are also predictive of therapeutic response. Whether or not the particular nosogenic cytokines represent the host's immune response to clonal myeloproliferation or a tumor-specific autocrine process is yet to be clarified. Similarly, the detrimental effect on survival might be mediated by either exacerbation of co-morbid conditions, such as cardiovascular disease, or by promoting clonal evolution and/or leukemic transformation. The latter are consistent with the general concept of a direct link between inflammation and oncogenesis.

Myelodysplastic syndrome (MDS) and PMF are both clonal stem cell diseases and share a number of clinical features, including ineffective erythropoiesis, bone marrow neoangiogenesis and an increased risk of leukemic transformation. These similarities, as well as the known role of immune dysregulation in MDS development and/or progression, ${ }^{4,5}$ led us to hypothesize that an altered plasma cytokine profile in MDS is both phenotypically and prognostically relevant and may also provide additional pathogenetic and therapeutic insights. To that end, in the current study, we performed a comprehensive plasma cytokine analysis in 78 patients with primary MDS. The main objectives of the study were: (i) describe the spectrum of abnormalities in cytokine levels and their comparison with normal controls; (ii) identify phenotypic and prognostic correlates of abnormally expressed cytokines; and (iii) compare plasma cytokine signatures of MDS and PMF.

\section{Materials and methods}

The current study was approved by the Mayo Clinic institutional review board. All patients provided informed written consent for study sample collection as well as permission for use in research. Inclusion to the current study required availability of archived plasma, bone marrow aspirate and biopsy and cytogenetic information at the time of first referral to the Mayo Clinic. The diagnoses of MDS and its subclassification were according to the World Health Organization criteria. ${ }^{6}$ To assure mature survival data, follow-up information was updated in 
June 2011 through review of patient histories and correspondence, social security death index or a telephone call to the patient or their local physician; 'date of last follow-up' reflected this time point and not the last time a patient was seen at the Mayo Clinic.

Peripheral blood was collected under a Mayo Clinic protocol for patients with myeloid malignancies and standard procedures were followed to centrifuge samples at $4{ }^{\circ} \mathrm{C}$ and store aliquots at $-80^{\circ} \mathrm{C}$. Concentrations of 30 plasma cytokines were analyzed in duplicates using Multiplex Bead-based Luminex Technology (Invitrogen, Carlsbad, CA, USA): IL-1 $\beta$, IL-1RA, IL-2, IL-2R, IL-4, IL-5, IL-6, IL-7, IL-8, IL-10, IL-12, IL-13, IL-15, IL-16, IL-17, epidermal growth factor, eotaxin, fibroblast growth factor-basic, granulocyte-macrophage colony-stimulating factor (GM-CSF), granulocyte colony-stimulating factor, HGF, IFN- $\alpha$, IFN- $\gamma$, IFN- $\gamma$-inducible protein 10/CXCL10, monocyte chemotactic protein-1, monokine induced by IFN- $\gamma$, MIP-1 $\alpha$, MIP-1 $\beta$, regulated on activation normally $\mathrm{T}$-cell expressed and secreted (RANTES), tumor necrosis factor- $\alpha$ and vascular endothelial growth factor. Measurements were performed on a Luminex 200 analyzer (Luminex Corporation, Austin, TX, USA) and resulting data were evaluated using the Xponent software (Luminex Corporation). The observed intensities of duplicate samples were averaged and mapped to a fitted curve derived from a serial dilution series of known cytokine standards; observed intensities below and above the standard range were marked as $0 \%$ and $100 \%$, respectively.

All statistical analyses were considered clinical and laboratory parameters obtained at the time of first referral to the Mayo Clinic, which usually coincided with the time of plasma collection for cytokine analysis. Differences in the distribution of continuous variables between categories were analyzed by either Mann-Whitney (for comparison of two groups) or Kruskal-Wallis (comparison of three or more groups) test. Patient groups with nominal variables were compared by $\chi^{2}$-test. Overall survival analysis was considered from the date of first referral to the Mayo Clinic (that is, date of plasma collection) to date of death (uncensored) or last contact (censored). Date of leukemic transformation replaced date of death, as the uncensored variable, for estimating leukemia-free survival. Overall and leukemia-free survival curves were prepared by the Kaplan-Meier method and compared by the log-rank test. Cox's proportional hazard regression model was used for multivariable analysis. $P$-values less than 0.05 were considered significant. The JMP statistical package (SAS Institute, Cary, NC, USA) was used for all calculations.

\section{Results}

The study population comprised of 78 consecutive patients with primary MDS (median age, 72 years; range $44-89$ years; $67 \%$ male) for whom an archived plasma sample collected at the time of referral to the Mayo Clinic was available for cytokine analysis (Table 1$)$. In all, 64 (82\%) patients were not receiving MDS-directed therapy at the time of sample collection, and the remaining were receiving erythropoiesis-stimulating agents (that is, recombinant erythropoietin) alone. In total, 57 (73\%) patients were treatment-naïve; nine $(11 \%)$ and five $(6 \%)$ patients had previously received hematopoietic growth factors and hypomethylating agents, respectively. The International Prognostic Scoring System (IPSS) distribution was as follows: low (28\%), intermediate-1 (47\%), intermediate-2 (18\%) and high (5\%); the corresponding distribution per the revised IPSS (IPSS-R) was as follows: very good 15 (19\%), good 33 (43\%), intermediate $13(17 \%)$, poor $3(4 \%)$ and very poor $13(17 \%)$. The World
Table 1 Clinical characteristics of 78 patients with de novo MDS with cytokine profiling available at the time of first referral at the Mayo Clinic

\begin{tabular}{|c|c|}
\hline Variables & $\begin{array}{c}\text { All patients with } \\
\text { cytokine profiling }(\mathrm{n}=78)\end{array}$ \\
\hline $\begin{array}{l}\text { Age (years), median (range) } \\
\text { Age }>65 \text { years, } n(\%) \\
\text { Males }(\%) \\
\text { Hemoglobin }(\mathrm{g} / \mathrm{dll}), \text { median (range) } \\
\text { Leukocyte count }\left(\times 10^{9} / \mathrm{l}\right) \text {, median (range) } \\
\text { Platelet count }\left(\times 10^{9} / \mathrm{l}\right) \text {, median (range) }\end{array}$ & $\begin{array}{l}72(44-89) \\
61(78 \%) \\
52(67 \%) \\
9.9(6.9-14.8) \\
3.4(1.1-14.9) \\
120(8-817)\end{array}$ \\
\hline $\begin{array}{l}\text { IPSS risk group, } \mathrm{n}(\%) \\
\text { Low } \\
\text { Intermediate-1 } \\
\text { Intermediate-2 } \\
\text { High }\end{array}$ & $\begin{array}{c}22(28 \%) \\
37(47 \%) \\
14(18 \%) \\
4(5 \%)\end{array}$ \\
\hline $\begin{array}{l}\text { IPSS-R risk group, } \mathrm{n}(\%) \\
\text { Very good } \\
\text { Good } \\
\text { Intermediate } \\
\text { Poor } \\
\text { Very poor }\end{array}$ & $\begin{array}{c}15(19 \%) \\
33(43 \%) \\
13(17 \%) \\
3(4 \%) \\
13(17 \%)\end{array}$ \\
\hline $\begin{array}{l}\text { WHO MDS category, n (\%) } \\
\text { RCMD/RCMD-RS } \\
\text { RAEB-1 } \\
\text { RAEB-2 } \\
\text { RARARS } \\
\text { Isolated del(5q) } \\
\text { MDS-u } \\
\text { RCUD (RT) }\end{array}$ & $\begin{array}{c}29(37 \%) \\
13(17 \%) \\
16(21 \%) \\
8(10 \%) \\
7(9 \%) \\
3(4 \%) \\
2(3 \%)\end{array}$ \\
\hline $\begin{array}{l}\text { BM blasts, } \mathrm{n}(\%) \\
\quad<5 \\
5-9 \\
10-19\end{array}$ & $\begin{array}{l}51(65 \%) \\
13(17 \%) \\
14(18 \%)\end{array}$ \\
\hline $\begin{array}{l}\text { IPSS karyotype, n (\%) } \\
\text { Favorable } \\
\text { Intermediate } \\
\text { Unfavorable }\end{array}$ & $\begin{array}{l}53(68 \%) \\
13(17 \%) \\
11(14 \%)\end{array}$ \\
\hline $\begin{array}{l}\text { IPSS-R karyotype, } \mathrm{n}(\%) \\
\text { Very good } \\
\text { Good } \\
\text { Intermediate } \\
\text { Poor } 1 \\
\text { Very poor }\end{array}$ & $\begin{aligned} & (5 \%) \\
53 & (69 \%) \\
11 & (14 \%) \\
1 & (1 \%) \\
8 & (10 \%)\end{aligned}$ \\
\hline $\begin{array}{l}\text { Circulating blasts } \geqslant 1 \%, n(\%) \\
\text { Hemoglobin }<10 \mathrm{~g} / \mathrm{dl}, n(\%) \\
\text { Red cell transfusion requiring, } n(\%) \\
\text { Platelets }<100 \times 10^{9} /, n(\%)\end{array}$ & $\begin{array}{l}16(21 \%) \\
43(55 \%) \\
40(51 \%) \\
34(44 \%)\end{array}$ \\
\hline $\begin{array}{l}\text { Treatment at sample date, } \mathrm{n}(\%) \\
\text { None } \\
\text { ESA }\end{array}$ & $\begin{array}{l}64(82 \%) \\
14(18 \%)\end{array}$ \\
\hline $\begin{array}{l}\text { Prior MDS treatment, n (\%) } \\
\text { None } \\
\text { Growth factors } \\
\text { Hypomethylating agents } \\
\text { Lenalidomide } \\
\text { Thalidomide } \\
\text { Other }\end{array}$ & $\begin{array}{c}57(73 \%) \\
9(11 \%) \\
5(6 \%) \\
3(4 \%) \\
2(3 \%) \\
2(3 \%)\end{array}$ \\
\hline $\begin{array}{l}\text { Follow-up, months, median (range) } \\
\text { Alive, } n(\%) \\
\text { Leukemic transformation, } n(\%)\end{array}$ & $\begin{array}{c}24(0-114) \\
32(41 \%) \\
6(7 \%)\end{array}$ \\
\hline
\end{tabular}

Abbreviations: BM, bone marrow; dl, deciliter; ESA, erythropoiesisstimulating agent; g, grams; IPSS, International Prognostic Scoring System; IPSS-R, Revised International Prognostic Scoring System; I, liter; MDS, myelodysplastic syndrome; MDS-u, MDS-unclassified; $n$, number; RA, refractory anemia; RAEB, refractory anemia with excess blasts; RARS, refractory anemia with ringed sideroblasts; $R C M D$, refractory cytopenia with multilineage dysplasia; RCMD-RS, refractory cytopenia with multilineage dysplasia and ringed sideroblasts; RCUD, refractory cytopenia with unilineage dysplasia; RT, refractory thrombocytopenia; WHO, World Health Organization. 
Table 2 Cytokines whose plasma levels are abnormally increased (or decreased) in 78 patients with de novo MDS and their relationship with age, gender and clinically relevant disease features at the time of first referral at the Mayo Clinic

\begin{tabular}{|c|c|c|c|c|c|c|c|c|c|c|c|c|c|}
\hline $\begin{array}{l}\text { Cytokines } \\
(\mathrm{pg} / \mathrm{ml})\end{array}$ & $\begin{array}{c}\text { Controls } \\
\text { median } \\
\text { (range), } \\
\mathrm{n}=35\end{array}$ & $\begin{array}{c}\text { MDS } \\
\text { patients } \\
\text { median } \\
\text { (range), } \\
\mathrm{n}=78\end{array}$ & P-value & $\begin{array}{l}\text { Age } \\
>65 \\
\text { years }\end{array}$ & $\begin{array}{l}\text { Female } \\
\text { gender }\end{array}$ & $\begin{array}{c}\text { WHO } \\
\text { MDS } \\
\text { category }\end{array}$ & $\begin{array}{c}\text { IPSS } \\
\text { category }\end{array}$ & $\begin{array}{c}R B C \\
\text { transfusion } \\
\text { depen- } \\
\text { dency }\end{array}$ & $\begin{array}{c}\text { IPSS } \\
\text { karyotype } \\
\text { category }\end{array}$ & $\begin{array}{c}B M \\
\text { blasts } \\
\text { category }\end{array}$ & $\begin{array}{c}P B \\
\text { blasts } \\
\geqslant 1 \%\end{array}$ & $\begin{array}{l}\text { Hemo- } \\
\text { globin } \\
<10 \mathrm{~g} / \mathrm{dl}\end{array}$ & $\begin{array}{c}\text { Platelets } \\
<100 \times \\
10^{9} / 1\end{array}$ \\
\hline IL-1RA & $203(2-419)$ & $240(0-13171)$ & 0.02 & NS & NS & NS & NS & NS & NS & NS & NS & 0.06 & NS \\
\hline $\mathrm{IL}-4$ & $7.2(0-33)$ & $41(0-5549)$ & 0.04 & NS & NS & NS & NS & NS & NS & NS & NS & NS & NS \\
\hline IL-6 & $0.6(0-9.1)$ & $4.6(0-236)$ & 0.0007 & NS & NS & NS & NS & NS & NS & NS & NS & NS & NS \\
\hline $\mathrm{IL}-7$ & $7.6(0-52)$ & $0(0-105)$ & 0.03 & NS & NS & NS & NS & NS & NS & NS & NS & NS & NS \\
\hline IL-8 & $3.3(0-18)$ & $17(0-714)$ & $<0.0001$ & NS & 0.03 & 0.02 & 0.01 & 0.007 & NS & 0.02 & NS & NS & NS \\
\hline IL-13 & $0(0-0)$ & $59(0-97)$ & $<0.0001$ & NS & NS & NS & NS & NS & NS & NS & NS & NS & NS \\
\hline IL-15 & $0(0-38)$ & $24(0-5324)$ & $<0.0001$ & NS & NS & NS & NS & NS & NS & NS & NS & NS & NS \\
\hline $\mathrm{IL}-17$ & $0(0-15)$ & $0.7(0-2844)$ & 0.03 & NS & NS & NS & NS & $0.05^{*}$ & NS & NS & NS & NS & 0.09 \\
\hline TNF- $\alpha$ & $0(0-15)$ & $3(0-287)$ & $<0.0001$ & NS & NS & 0.04 & NS & NS & NS & NS & NS & NS & NS \\
\hline G-CSF & $33(0-373)$ & $145(0-1388)$ & $<0.0001$ & NS & NS & NS & NS & NS & NS & NS & NS & NS & NS \\
\hline IFN- $\gamma$ & $5.5(0-23)$ & $22.2(0-139.1)$ & $<0.0001$ & NS & NS & NS & NS & NS & NS & NS & NS & NS & NS \\
\hline MIP-1 $1 \beta$ & $21.8(4.4-91)$ & $41(0-1415)$ & 0.04 & NS & NS & NS & NS & NS & NS & NS & NS & NS & NS \\
\hline $\mathrm{HGF}$ & $129(0-433)$ & $240(0-2313)$ & $<0.0001$ & NS & NS & NS & NS & NS & NS & NS & NS & NS & NS \\
\hline CXCL10 & $22(4-97)$ & $107(0-1414)$ & $<0.0001$ & NS & NS & 0.09 & 0.08 & NS & NS & NS & 0.02 & NS & 0.02 \\
\hline MIG & $19.4(0-86)$ & $72.4(0-1473)$ & $<0.0001$ & NS & NS & NS & NS & NS & NS & NS & NS & NS & NS \\
\hline Eotaxin & $47.5(7.6-155.5)$ & $60.9(2.2-690)$ & 0.02 & NS & NS & NS & NS & NS & $0.02^{*}$ & NS & NS & NS & NS \\
\hline RANTES & $4130(0-34347)$ & $59.5(0-18294)$ & 0.0005 & NS & NS & NS & NS & NS & NS & NS & NS & 0.08 & 0.006 \\
\hline MCP-1 & $173(61-342)$ & $247(0-4306)$ & 0.002 & 0.03 & NS & NS & NS & NS & NS & NS & NS & NS & NS \\
\hline VEGF & $1(0-2.7)$ & $3.4(0-40.5)$ & 0.009 & NS & NS & NS & NS & NS & NS & NS & NS & NS & 0.09 \\
\hline
\end{tabular}

Abbreviations: BM, bone marrow; CXCL10, C-X-C motif chemokine 10; dl, deciliter; IFN, interferon; IL, interleukin; IPSS, International Prognostic Scoring System; g, grams; G-CSF, granulocyte colony-stimulating factor; HGF, hepatocyte growth factor; I, liter; MCP-1, monocyte chemotactic protein-1; MDS, myelodysplastic syndrome; MIG, monokine induced by IFN- $\gamma$; MIP, macrophage inflammatory protein; ml, milliliter; $n$, number; NS, not significant $(P>0.05)$; PB, peripheral blood; pg, picogram; RANTES, regulated on activation normally T-cell expressed and secreted; RBC, red blood cell; TNF, tumor necrosis factor; VEGF, vascular endothelial growth factor; WHO, World Health Organization.

Disease-relevant characteristics significantly associated with increased cytokine levels, except as indicated by asterisk (*).

Health Organization subgroups were as follows: refractory cytopenia with multilineage dysplasia/refractory cytopenia with multilineage dysplasia and ringed sideroblasts: 29 (37\%); refractory anemia with excess blast-1: 13 (17\%); refractory anemia with excess blast-2: 16 (21\%); refractory anemia/ refractory anemia with ringed sideroblasts: $8(10 \%)$; MDS with isolated $\operatorname{del}(5 \mathrm{q})$ : 7 (9\%); MDS-unclassified: 3 (4\%); and refractory cytopenia with unilineage dysplasia (refractory thrombocytopenia): 2 (3\%). Other risk-relevant information, such as the proportion of patients with red cell transfusion dependency, unfavorable karyotype and thrombocytopenia, is outlined in Table 1.

Plasma cytokine levels were measured in 78 patients with primary MDS (Table 2) and 35 normal controls. Compared to normal controls, the levels of 19 cytokines were significantly different for MDS patients: all were increased except for RANTES (Table 2). Phenotypic correlates in MDS included increased levels of IL-8 with higher IPSS risk category, red cell transfusion dependency, higher bone marrow blast count and female gender; increased levels of CXCL10 with the presence of circulating peripheral blood blasts and thrombocytopenia; decreased levels of eotaxin with IPSS-defined unfavorable karyotype; increased levels of RANTES with thrombocytopenia; and decreased levels of IL-17 with red cell transfusion dependency; with other associations as outlined in Table 2.

Median follow-up from the time of plasma sample collection was 24 months (range, 0-114 months); for the 32 living patients, the median follow-up was 31 months (range, 0-114 months). During this period, 46 deaths (59\%) were documented in this cohort. A number of clinical and laboratory parameters were identified as being associated with shortened survival by using Cox proportional hazards regression models (Table 3). Of the 18 cytokines that were abnormally elevated in MDS patients, only three cytokines were associated with shortened survival on univariate analysis: CXCL10 $(P<0.01)$, IL-6 $(P=0.02)$ and IL-7 $(P=0.02) \quad($ Table 3$)$. All three cytokines maintained their individual significant association with shortened survival when the Cox model was adjusted for the IPSS or IPSS-R (Table 3). Consistent with this finding, there was no significant difference in CXCL-10, IL-7 or IL-6 levels between IPSS low- and high-risk subgroups, or refractory anemia/refractory anemia with ringed sideroblasts /isolated $(\operatorname{del}(5 q) / R C U D$ vs refractory anemia with excess blast-2 subgroups ( $P>0.05)$.

On multivariable analysis that included the three cytokines, increased levels of CXCL10 $(P<0.01)$ and IL-7 $(P=0.02)$ were identified as predictors of shortened survival, whereas IL-6 maintained borderline significance $(P=0.07)$. The survival association for CXCL10 $(P=0.02)$ and IL-7 $(P=0.04)$ remained significant when the Cox model was adjusted for IPSS or IPSS-R, age, red cell transfusion dependence and thrombocytopenia (IL-6 levels remained borderline significant in this analysis).

Based on the strength of their association with survival, a model for risk categorization of MDS patients based on increased plasma levels of IL-6, IL-7 and CXCL10 was developed. For consistency with a previous similar analysis in PMF patients, a cytokine level that exceeded 3 standard deviations from the normal mean (>3 s.d.) was defined as being significantly elevated for the current analysis. ${ }^{2}$ MDS patients with normal plasma levels of IL-6, IL-7 and CXCL10 lived significantly longer ( $n=20$; median survival 76 months) as compared to those with increased levels of one or more of the three cytokines $(n=57$; median survival 25 months $)(P<0.01)$ (Figure 1). The risk-categorization model retained its predictive significance when adjusted for IPSS (or IPSS-R), red cell transfusion dependence and thrombocytopenia using a Cox 
Table 3 Overall survival using Cox proportional hazards model (univariate analysis)

\begin{tabular}{|c|c|c|}
\hline Variable & P-value & $\begin{array}{l}\text { Risk ratio } \\
(95 \% \mathrm{Cl})\end{array}$ \\
\hline $\begin{array}{l}\text { Age (years) } \\
\text { Hemoglobin (g/dl) } \\
\text { RBC transfusion dependency } \\
\text { Platelet count }<100 \times 100^{9} / 1 \\
\text { IPSS category } \\
\text { IPSS-R category }\end{array}$ & $\begin{array}{l}0.04 \\
0.02 \\
0.006 \\
0.06 \\
0.004 \\
0.2\end{array}$ & $\begin{array}{l}2.3(1.3-4.2) \\
1.8(0.97-3.2)\end{array}$ \\
\hline $\begin{array}{l}\text { WHO MDS category } \\
\text { RAEB vs RA/RARS/del(5q)/RCUD } \\
\text { RAEB vs RCMD/RCMD-RS } \\
\text { RCMD/RCMD-RS vs RA/RARS/ } \\
\text { del(5q)/RCUD }\end{array}$ & $\begin{array}{l}0.002 \\
0.0006 \\
0.01 \\
0.2\end{array}$ & $\begin{array}{c}4.2(1.8-11.2) \\
2.3(1.2-4.6) \\
187(0.8-4.8)\end{array}$ \\
\hline $\begin{array}{l}\text { Presence of circulating blasts } \\
\text { BM blast category }(<5 \% \text { vs } \geqslant 5 \%)\end{array}$ & $\begin{array}{l}0.01 \\
0.005\end{array}$ & $\begin{array}{l}2.5(1.2-4.6) \\
2.5(1.3-4.6)\end{array}$ \\
\hline $\begin{array}{l}\text { IL-6 level (continuous) } \\
\text { Unadjusted } \\
\text { Adjusted for IPSS } \\
\text { Adjusted for IPSS-R }\end{array}$ & $\begin{array}{l}0.02 \\
0.04 \\
0.04\end{array}$ & \\
\hline $\begin{array}{l}\text { CXCL10 level (continuous) } \\
\text { Unadjusted } \\
\text { Adjusted for IPSS } \\
\text { Adjusted for IPSS-R }\end{array}$ & $\begin{array}{l}0.002 \\
0.01 \\
0.02\end{array}$ & \\
\hline $\begin{array}{l}\text { IL-7 level (continuous) } \\
\text { Unadjusted } \\
\text { Adjusted for IPSS } \\
\text { Adjusted for IPSS-R }\end{array}$ & $\begin{array}{l}0.02 \\
0.01 \\
0.03\end{array}$ & \\
\hline
\end{tabular}

Abbreviation: $\mathrm{Cl}$, confidence interval; CXCL10, C-X-C motif chemokine 10; dl, deciliter; g, grams; IL, interleukin; IPSS, International Prognostic Scoring System; IPSS-R, Revised International Prognostic Scoring System; I, liter; MDS, myelodysplastic syndrome; RA, refractory anemia; RAEB, refractory anemia with excess blasts; RARS, refractory anemia with ringed sideroblasts; RBC, red blood cell; $\mathrm{RCMD}$, refractory cytopenia with multilineage dysplasia; RCMD-RS, refractory cytopenia with multilineage dysplasia and ringed sideroblasts; RCUD, Refractory cytopenia with unilineage dysplasia; WHO, World Health Organization.

proportional hazards regression model $(P=0.03$; Risk ratio $=2.7,95 \%$ confidence interval $=1.1-8.2$ ).

In the present cohort, complete follow-up information (up to June 2011) including cause of death (where applicable) was available for 50 MDS patients (64\%); of these, six patients $(12 \%)$ were confirmed to have undergone leukemic transformation. Leukemia-free survival was significantly associated with increased IL-6 level $(P=0.01)$ and borderline associated with increased CXCL10 level $(P=0.09)$, but not with increased IL-7 level $(P=0.8)$. The association between inferior leukemia-free survival and increased IL-6 was not accounted for by age, transfusion dependence, IPSS, IPSS-R, World Health Organization MDS category, thrombocytopenia, IPSS-defined karyotype or BM blast category $(P<0.05)$. The present findings were not affected when the analysis was extended to the entire cohort; that is, the remaining 28 MDS patients were included after censoring for leukemic transformation at the date of last followup (data not shown).

Given recent data regarding a similar significant association of cytokines with specific phenotypic features as well as clinical outcome (overall and leukemia-free survival) in $\mathrm{PMF}^{2}$ we sought to compare plasma cytokine levels between the two diseases (that is, MDS and PMF). Of the 31 cytokines interrogated, plasma levels of all except IL-2, IL-5, IL-8,

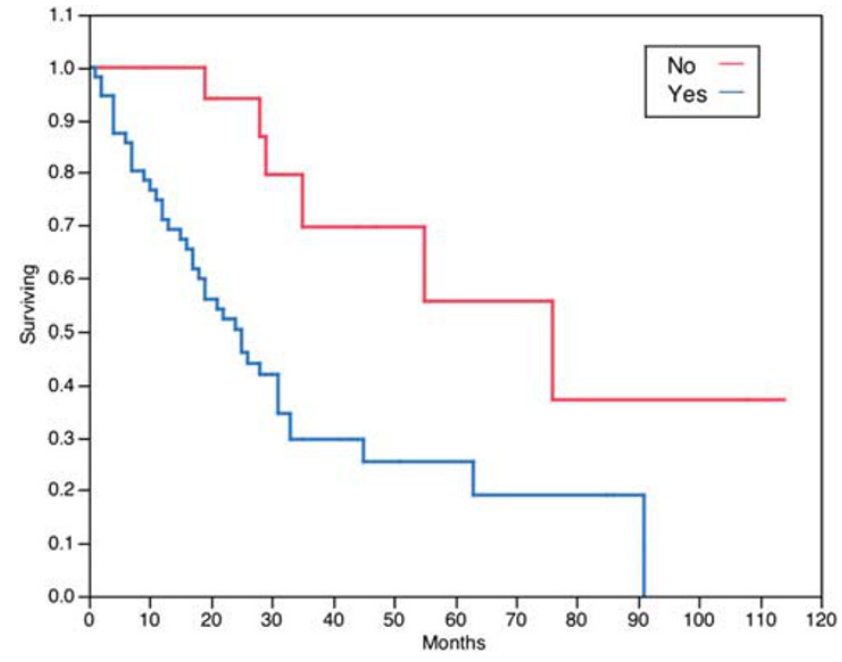

Figure 1 Survival data for 78 patients with primary MDS stratified based on plasma levels of CXCL10, IL-7 and IL-6: (i) normal levels of all three cytokines (red curve) or (ii) increased ( $>3$ standard deviations of the normal mean level) level(s) of one or more of the aforementioned cytokines (blue curve). MDS patients with increased cytokine level(s) had a significantly inferior survival $(n=57$; median survival $=25$ months) as compared to those with normal levels of all three cytokines $(n=20$; median survival approximately 76 months) (log-rank $P$-value $=0.002$ ). This association with inferior overall survival was sustained on multivariate analysis.

granulocyte-macrophage colony-stimulating factor, monocyte chemotactic protein-1 and vascular endothelial growth factor were significantly different between the two disease groups (Table 4).

\section{Discussion}

The MDS are a clinically and molecularly heterogeneous group of clonal hematopoietic stem cell disorders that are singularly characterized by peripheral blood cytopenias from ineffective hematopoiesis and an increased but variable risk of leukemic transformation. ${ }^{7}$ Dysregulation of the immune system is thought to play an important role in MDS pathogenesis by promoting the development and/or progression of disease. The best evidence in this regard comes from the proven efficacy of immunosuppressive therapies such as anti-thymocyte globulin, cyclosporin A and alemtuzumab in at least a subset of MDS patients where autoimmunity is the central pathophysiological mechanism, ${ }^{8-11}$ and also the frequent concurrence of autoimmune conditions with MDS. ${ }^{12}$ Further evidence comes from a large, populationbased, case-control study using registry data, which demonstrated that chronic immune stimulation, represented by a wide range of infectious or autoimmune conditions, was significantly associated with an increased risk of developing MDS or acute myeloid leukemia. $^{13}$

Various aspects of immune dysregulation have been studied in MDS, including the antigen-driven expansion of autoreactive $\mathrm{CD} 8+\mathrm{T}$ cells of restricted $\mathrm{V}_{\beta}$ repertoire that are capable of suppressing hematopoietic colony growth in vitro. ${ }^{14,15}$ Evidence for impaired immune surveillance comes from the presence of dysfunctional natural killer (NK) cells with decreased cytolytic activity possibly reflecting expansion of clonal NK cells and/or decreased expression of NK activating receptors, ${ }^{16,17}$ and also from the presence of increased numbers of peripheral blood 
Comp

\section{Cytokines (pg/ml)}

IL-1 $\beta$

IL-1RA

IL-2

IL-2R

IL-4

EGF

IL-5

IL-6

IL-7

IL-8

IL-10

FGF-b

IL-12

IL-13

IL-15

IL-17

TNF- $\alpha$

G-CSF

IFN- $\alpha$

IFN- $\gamma$

GM-CSF

MIP-1 $\alpha$

MIP-1 $\beta$

HGF

CXCL10

MIG

EOTAXIN

RANTES

MCP-1

VEGF

(1)

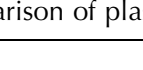

Controls median
(range), $\mathrm{n}=35$

$4(0-49)$
$203(2-419)$
$6.1(0-28)$
$217(0-507)$
$7.2(0-33)$
$32.7(0-356)$

$0(0-8)$

$0.6(0-9.1)$

$7.6(0-52)$

$3.3(0-18)$

$4.8(2.3-51)$

$16(0-67)$

100 (35-182)

$0(0-0)$

0 (0-38)

$0(0-15)$

$0(0-15)$

$33(0-373)$

27.6 (0-96)

$5.5(0-23)$

$0(0-172)$

$0(0-112)$

21.8 (4.4-91)

$129(0-433)$

22 (4-97)

$19.4(0-86)$

$47.5(7.6-156)$

4130 (0-34 347)

173 (61-342)

$1(0-2.7)$

\begin{tabular}{|c|c|c|}
\hline $\begin{array}{c}\text { MDS patients median } \\
\text { (range), } \mathrm{n}=78\end{array}$ & $\begin{array}{l}\text { PMF patients median } \\
\text { (range), } \mathrm{n}=127\end{array}$ & P-value \\
\hline $4.8(0-1858)$ & $10.8(0-3576)$ & 0.03 \\
\hline $240(0-13171)$ & 552 (37-9991) & $<0.0001$ \\
\hline $7.5(0-2554)$ & $5.1(0-1562)$ & NS \\
\hline $236(0-11027)$ & 556 (91-3956) & $<0.0001$ \\
\hline $41(0-5549)$ & $6.4(0-580)$ & 0.01 \\
\hline $17.7(0-1611)$ & 31.7 (0-3186) & 0.003 \\
\hline $1.9(0-7.4)$ & $0(0-3998)$ & NS \\
\hline $4.6(0-236)$ & $6.3(0-186)$ & 0.03 \\
\hline $0(0-105)$ & $7.5(0-475)$ & 0.0001 \\
\hline $17(0-714)$ & $14.3(0-1156)$ & NS \\
\hline $10.3(0-46)$ & 12.5 (2-2009) & $<0.0001$ \\
\hline $18.9(0-1805)$ & $25.1(0-861)$ & 0.04 \\
\hline 95 (0-2960) & $192(18-1883)$ & $<0.0001$ \\
\hline $59(0-97)$ & $0(0-4909)$ & 0.001 \\
\hline $24(0-5324)$ & $0(0-2671)$ & $<0.0001$ \\
\hline 0.7 (0-2844) & $0(0-425)$ & 0.0004 \\
\hline $3(0-287)$ & $0(0-400)$ & $<0.0001$ \\
\hline $145(0-1388)$ & $45(0-888)$ & 0.0002 \\
\hline $16(0-1463)$ & $42(0-1021)$ & 0.001 \\
\hline $22.2(0-139.1)$ & $42(0-1021)$ & 0.0001 \\
\hline $0(0-261)$ & $0(0-2950)$ & NS \\
\hline $0(0-2139)$ & $25.4(0-1305)$ & $<0.0001$ \\
\hline $41(0-1415)$ & 65.7 (0-1935) & $<0.0001$ \\
\hline $240(0-2313)$ & $391(0-11572)$ & $<0.0001$ \\
\hline $107(0-1414)$ & $72(5.3-755)$ & 0.0008 \\
\hline $72.4(0-1473)$ & $49(0-971)$ & 0.0009 \\
\hline $60.9(2.2-690)$ & $40.2(5.4-274)$ & $<0.0001$ \\
\hline 59.5 (0-18294) & 4881 (0-801 880) & $<0.0001$ \\
\hline $247(0-4306)$ & $222(62-1705)$ & NS \\
\hline $3.4(0-40.5)$ & $2.3(0-47)$ & NS \\
\hline
\end{tabular}

Abbreviations: CXCL10, C-X-C motif chemokine 10; FGF-b, fibroblast growth factor-basic; G-CSF, granulocyte colony-stimulating factor; GM-CSF, granulocyte-macrophage colony-stimulating factor; HGF, hepatocyte growth factor; IFN- $\gamma$, interferon- $\gamma$; IL, interleukin; MCP-1, monocyte chemotactic protein-1; MDS, myelodysplastic syndrome; MIG, monokine induced by IFN- $\gamma$; MIP, macrophage inflammatory protein; $n$, number; NS, not significant $(P>0.05)$; pg, picogram; PMF, primary myelofibrosis; TNF, tumor necrosis factor; RANTES, regulated on activation normally Tcell expressed and secreted; VEGF, vascular endothelial growth factor.

T regulatory cells (defined as CD4,+ CD25 high Foxp3 + T cells) of polyclonal origin, particularly in advanced MDS patients. ${ }^{18,19}$ Another possible mechanism is the inflammatory cytokinedriven expansion of myeloid-derived suppressor cells that may further contribute to the development of immune tolerance in MDS. ${ }^{5}$

MDS patients exhibit an abnormal cytokine milieu that likely stems from the interaction of the MDS clone with bone marrow stromal cells and infiltrating immune effector cells that underpins the persistent low-level inflammatory state. Although much of the attention has been focused on the study of individual myelosuppressive/pro-apoptotic or pro-inflammatory cytokines such as tumor necrosis factor- $\alpha$, tumor growth factor- $\beta$, IFN- $\gamma$ or IL-6, ${ }^{20-26}$ only two previous studies to our knowledge have attempted to comprehensively profile circulating cytokinechemokine levels in MDS patients. 27,28 In one study of 162 acute myeloid leukemia and 100 MDS patients who profiled 27 cytokines, a combined analysis of both patient groups showed that serum (not plasma) levels of CSF3, IL-1RA, IL-8, IL-12, IL-15, CXCL10, tumor necrosis factor $-\alpha$ and IL-17 were significantly elevated relative to normal controls. ${ }^{27}$ Unexpectedly, the expression profiles of 24 of the 27 cytokines were statistically indistinguishable between acute myeloid leukemia and MDS patients. Although individual cytokine levels were not correlated with clinical or laboratory features, elevated levels of IL-4 and MIP-1 $\alpha$ were associated with longer survival in MDS; the latter observation was however not confirmed within the context of other known prognostic factors in MDS in a multivariate analysis. In the other study of 33 aplastic anemia and 57 MDS patients, plasma levels of tumor necrosis factor $-\alpha$, IL-6, MIP- $1 \alpha$, MIP-1 $\beta$ and HGF were increased in MDS relative to aplastic anemia or normal controls. ${ }^{28}$ Although distinct cytokine signature profiles were identified for $\mathrm{AA}$ and MDS patients, there were no data presented regarding clinical or laboratory correlates of individual cytokines or any information regarding association of cytokine levels with clinical outcome.

The current study adds significant novel information relative to the two aforementioned studies of cytokine profiling in MDS. First, we measured cytokine levels in plasma, which may be an advantage given the significant differences in levels of soluble protein factors between plasma relative to serum due to activation of the coagulation cascade in the latter. Second, the vast majority of MDS patients in our study were not receiving active therapy at the time of sample collection and none were receiving disease-modifying therapy that could potentially alter the disease-inherent baseline cytokine profile. Third, the followup of patients in our cohort was mature, thereby allowing for full analysis of the effect of cytokine levels on overall survival and leukemia-free survival. Fourth, availability of a fully annotated clinical database allowed a detailed assessment of association of cytokine levels with clinical or laboratory features. Fifth, updated prognostic information per the IPSS-R was incorporated and the added prognostic impact of cytokine levels on clinical outcome was confirmed within this context. Sixth, a full comparison of cytokine profiles between MDS and PMF was conducted given the disease similarities in terms of anemia 
prevalence, presence of constitutional symptoms and increased risk of bone marrow failure and leukemic transformation.

In the current study of MDS patients, IL-8 and CXCL10 stand out as the most relevant cytokines in terms of phenotypic correlations and CXCL10, IL-7 and IL-6 in terms of their prognostic impact. Shortened overall survival was predicted by increased levels of the latter three cytokines independent of conventional prognostic factors in MDS that included IPSS or IPSS-R, ${ }^{29,30}$ age, $^{31,32}$ red cell transfusion dependence ${ }^{33,34}$ and thrombocytopenia. ${ }^{31,32}$ This suggests a significant pathogenetic contribution of the aforementioned cytokines in disease development and/or progression that is independent of the MDS clone and confirms the importance of dysregulated immunity in MDS. Accordingly, the cytokine data could be effectively combined into a model for risk categorization, wherein normal levels of all three cytokines identified MDS patients with significantly longer survival relative to those with elevated levels of one or more cytokines. Although the predictive value of this model was confirmed to be independent of known prognostic factors in MDS for the overall cohort, the analysis was not extended to IPSS subsets given the limited number of patients in the current study.

Death in MDS patients results from the competing phenomena of worsening co-morbidities, bone marrow failure and leukemic transformation. In an analysis of the association of specific cytokines with the risk of leukemic transformation, we found that two of the three cytokines that were associated with inferior overall survival (IL-6, and to a lesser extent CXCL10) were also predictive for inferior leukemia-free survival in MDS, independent of previously established prognostic factors in this regard. This observation suggests an additional permissive role of specific cytokines in the process of clonal evolution in MDS and identifies at least one reason for the inferior survival of patients with increased cytokine levels. Additional studies are needed to ascertain whether elevated cytokine levels are also implicated in excess deaths due to increased progression of co-morbidities such as cardiovascular disease, and so on.

Observations from the current study reinforce the concept of distinct and prognostically relevant plasma cytokine signatures in hematological malignancies. Although the plasma cytokine profile between MDS and PMF is substantially dissimilar, it is interesting to note that CXCL10 was identified as an independent prognostic indicator in both diseases and also large-cell lymphoma. ${ }^{1,2}$ The particular observation suggests a general host response to a disease state with an aggressive biology rather than a tumor-specific cytokine release. Also of note is the observation that the other prognostically relevant cytokines were different between MDS (IL-6, IL-7) and PMF (IL-2R, IL-8, IL-12, IL-15) or large-cell lymphoma (IL-2R, IL-8, IL-10, IL-12, CXCL9). In this instance, some of the nosogenic cytokines might be under the control of a tumor-specific autocrine process and therefore also relevant to disease pathogenesis. With regards to MDS-relevant cytokines, IL-7 was initially identified as a growth factor for B-lymphocyte progenitors and is now known to be an important regulator for many aspects of B-cell lymphopoiesis. ${ }^{35}$ IL-6 is a pro-inflammatory cytokine, which has an important role in activating the immune system, particularly in the transition from an innate to an acquired immune response. ${ }^{36}$ CXCL10 is a chemokine induced by IFN- $\gamma$, and is also classified as an inflammatory cytokine; this chemokine binds to CXCR3 and regulates the immune response through the activation and recruitment of various immune-competent cells. ${ }^{37}$

The observations from the current study may also have therapeutic implications, an aspect that is exemplified by the known activity of drugs such as thalidomide and lenalidomide that have broad immunomodulatory activity in MDS. ${ }^{38}$ Patients with MDS face not only shortened survival, but also a major compromise in quality of life as a result of frequent red blood cell transfusion requirement and other complications such as infections and bleeding. It is possible that the specific aforementioned cytokines or their downstream signaling intermediates can be therapeutically targeted to alleviate clinically relevant aspects of MDS.

\section{Conflict of interest}

The authors declare no conflict of interest.

\section{Acknowledgements}

A Pardanani received a research grant from the Henry J Predolin Foundation for Research in Leukemia.

\section{Author contributions}

AP and AT designed the study, contributed patient samples, analyzed the data and wrote the paper; $\mathrm{AA}-\mathrm{K}$ and $\mathrm{KB}$ contributed patient samples; $\mathrm{CAH}$ reviewed bone marrow histology; and TLL and CF performed the laboratory studies.

\section{References}

1 Ansell SM, Maurer MJ, Ziesmer SC, Slager SL, Habermann TM, Link $\mathrm{B}$ et al. Pretreatment serum cytokines predict early disease relapse and a poor prognosis in diffuse large B-cell lymphoma (DLBCL) patients. Blood (ASH Annual Meeting Abstracts) 2010; 116: 436 .

2 Tefferi A, Vaidya R, Caramazza D, Finke C, Lasho T, Pardanani A. Circulating interleukin (IL)-8, IL-2R, IL-12, and IL-15 levels are independently prognostic in primary myelofibrosis: a comprehensive cytokine profiling study. J Clin Oncol 2011; 29: 1356-1363.

3 Pardanani A, Begna K, Finke C, Lasho T, Tefferi A. Circulating levels of MCP-1, sIL-2R, IL-15, and IL-8 predict anemia response to pomalidomide therapy in myelofibrosis. Am J Hematol 2011; 86: 343-345.

4 Olnes MJ, Sloand EM. Targeting immune dysregulation in myelodysplastic syndromes. JAMA 2011; 305: 814-819.

5 Warlick ED, Miller JS. Myelodysplastic syndromes: the role of the immune system in pathogenesis. Leuk Lymphoma 2011; e-pub ahead of print 12 June 2011.

6 Vardiman JW, Thiele J, Arber DA, Brunning RD, Borowitz MJ, Porwit A et al. The 2008 revision of the World Health Organization (WHO) classification of myeloid neoplasms and acute leukemia: rationale and important changes. Blood 2009; 114: 937-951.

7 Tefferi A, Vardiman JW. Myelodysplastic syndromes. N Engl J Med 2009; 361: 1872-1885.

8 Lim ZY, Killick S, Germing U, Cavenagh J, Culligan D, Bacigalupo $\mathrm{A}$ et al. Low IPSS score and bone marrow hypocellularity in MDS patients predict hematological responses to antithymocyte globulin. Leukemia 2007; 21: 1436-1441.

9 Jonasova A, Neuwirtova R, Cermak J, Vozobulova V, Mocikova K, Siskova $\mathrm{M}$ et al. Cyclosporin A therapy in hypoplastic MDS patients and certain refractory anaemias without hypoplastic bone marrow. Br J Haematol 1998; 100: 304-309.

10 Sloand EM, Olnes MJ, Shenoy A, Weinstein B, Boss C, Loeliger K et al. Alemtuzumab treatment of intermediate-1 myelodysplasia patients is associated with sustained improvement in blood counts and cytogenetic remissions. J Clin Oncol 2010; 28: 5166-5173.

11 Sloand EM, Wu CO, Greenberg P, Young N, Barrett J. Factors affecting response and survival in patients with myelodysplasia treated with immunosuppressive therapy. J Clin Oncol 2008; 26: 2505-2511.

12 Anderson LA, Pfeiffer RM, Landgren O, Gadalla S, Berndt SI, Engels EA. Risks of myeloid malignancies in patients with autoimmune conditions. Br J Cancer 2009; 100: 822-828. 
13 Kristinsson SY, Bjorkholm $M$, Hultcrantz $M$, Derolf AR, Landgren O, Goldin LR. Chronic immune stimulation might act as a trigger for the development of acute myeloid leukemia or myelodysplastic syndromes. J Clin Oncol 2011; 29: 2897-2903.

14 Molldrem JJ, Jiang YZ, Stetler-Stevenson M, Mavroudis D, Hensel $\mathrm{N}$, Barrett AJ. Haematological response of patients with myelodysplastic syndrome to antithymocyte globulin is associated with a loss of lymphocyte-mediated inhibition of CFU-GM and alterations in T-cell receptor Vbeta profiles. Br J Haematol 1998; 102: 1314-1322.

15 Epperson DE, Nakamura R, Saunthararajah Y, Melenhorst J, Barrett AJ. Oligoclonal $\mathrm{T}$ cell expansion in myelodysplastic syndrome: evidence for an autoimmune process. Leuk Res 2001; 25: 1075-1083.

16 Kiladjian JJ, Bourgeois E, Lobe I, Braun T, Visentin G, Bourhis JH et al. Cytolytic function and survival of natural killer cells are severely altered in myelodysplastic syndromes. Leukemia 2006; 20: $463-470$.

17 Epling-Burnette PK, Bai F, Painter JS, Rollison DE, Salih HR, Krusch $\mathrm{M}$ et al. Reduced natural killer (NK) function associated with high-risk myelodysplastic syndrome (MDS) and reduced expression of activating NK receptors. Blood 2007; 109: 4816-4824.

18 Kordasti SY, Ingram W, Hayden J, Darling D, Barber L, Afzali B et al. CD4+CD25high Foxp3+ regulatory T cells in myelodysplastic syndrome (MDS). Blood 2007; 110: 847-850.

19 Kotsianidis I, Bouchliou I, Nakou E, Spanoudakis E, Margaritis D, Christophoridou AV et al. Kinetics, function and bone marrow trafficking of CD4+CD25+FOXP3+ regulatory $\mathrm{T}$ cells in myelodysplastic syndromes (MDS). Leukemia 2009; 23: 510-518.

20 Stasi R, Brunetti M, Bussa S, Conforti M, Martin LS, La Presa M et al. Serum levels of tumour necrosis factor-alpha predict response to recombinant human erythropoietin in patients with myelodysplastic syndrome. Clin Lab Haematol 1997; 19: 197-201.

21 Tsimberidou AM, Estey E, Wen S, Pierce S, Kantarjian H, Albitar M et al. The prognostic significance of cytokine levels in newly diagnosed acute myeloid leukemia and high-risk myelodysplastic syndromes. Cancer 2008; 113: 1605-1613.

22 Hsu HC, Lee YM, Tsai WH, Jiang ML, Ho CH, Ho CK et al. Circulating levels of thrombopoietic and inflammatory cytokines in patients with acute myeloblastic leukemia and myelodysplastic syndrome. Oncology 2002; 63: 64-69.

23 Wang XS, Shi Q, Williams LA, Cleeland CS, Mobley GM, Reuben JM et al. Serum interleukin-6 predicts the development of multiple symptoms at nadir of allogeneic hematopoietic stem cell transplantation. Cancer 2008; 113: 2102-2109.

24 Kondo A, Yamashita T, Tamura H, Zhao W, Tsuji T, Shimizu M et al. Interferon-gamma and tumor necrosis factor-alpha induce an immunoinhibitory molecule, B7-H1, via nuclear factor-kappaB activation in blasts in myelodysplastic syndromes. Blood 2010 116: $1124-1131$.
25 Raza A, Mundle S, Shetty V, Alvi S, Chopra H, Span L et al. A paradigm shift in myelodysplastic syndromes. Leukemia 1996; 10: $1648-1652$

26 Shetty V, Mundle S, Alvi S, Showel M, Broady-Robinson L, Dar S et al. Measurement of apoptosis, proliferation and three cytokines in 46 patients with myelodysplastic syndromes. Leuk Res 1996; 20: 891-900.

27 Kornblau SM, McCue D, Singh N, Chen W, Estrov Z, Coombes KR. Recurrent expression signatures of cytokines and chemokines are present and are independently prognostic in acute myelogenous leukemia and myelodysplasia. Blood 2010; 116: 4251-4261.

28 Feng X, Scheinberg P, Wu CO, Samsel L, Nunez O, Prince C et al. Cytokine signature profiles in acquired aplastic anemia and myelodysplastic syndromes. Haematologica 2011; 96: 602-606.

29 Greenberg PL. Risk factors and their relationship to prognosis in myelodysplastic syndromes. Leuk Res 1998; 22(Suppl 1): S3-S6.

30 Greenberg P, Tuechler H, Schanz J, Sole F, Bennett JM, Garcia-Manero G et al. Revised International Prognostic Scoring System (IPSS-R), developed by the International Prognostic Working Group for Prognosis in MDS. Leuk Res 2011; 35(Suppl 1): S6.

31 Garcia-Manero G, Shan J, Faderl S, Cortes J, Ravandi F, Borthakur $\mathrm{G}$ et al. A prognostic score for patients with lower risk myelodysplastic syndrome. Leukemia 2008; 22: 538-543.

32 Kantarjian H, O'Brien S, Ravandi F, Cortes J, Shan J, Bennett JM et al. Proposal for a new risk model in myelodysplastic syndrome that accounts for events not considered in the original International Prognostic Scoring System. Cancer 2008; 113: 1351-1361.

33 Malcovati L, Germing U, Kuendgen A, Della Porta MG, Pascutto C, Invernizzi R et al. Time-dependent prognostic scoring system for predicting survival and leukemic evolution in myelodysplastic syndromes. J Clin Oncol 2007; 25: 3503-3510.

34 Malcovati L, Porta MG, Pascutto C, Invernizzi R, Boni M, Travaglino $\mathrm{E}$ et al. Prognostic factors and life expectancy in myelodysplastic syndromes classified according to WHO criteria: a basis for clinical decision making. J Clin Oncol 2005; 23: 7594-7603.

35 Milne CD, Paige CJ. IL-7: a key regulator of B lymphopoiesis. Sem Immunol 2006; 18: 20-30.

36 Scheller J, Chalaris A, Schmidt-Arras D, Rose-John S. The pro- and anti-inflammatory properties of the cytokine interleukin-6. Biochim Biophys Acta 2011; 1813: 878-888.

37 Lee EY, Lee ZH, Song YW. CXCL10 and autoimmune diseases. Autoimmun Rev 2009; 8: 379-383.

38 Kotla V, Goel S, Nischal S, Heuck C, Vivek K, Das B et al. Mechanism of action of lenalidomide in hematological malignancies. J Hematol Oncol 2009; 2: 36.

(c) This work is licensed under the Creative Commons Attribution-NonCommercial-No Derivative Works 3.0 Unported License. To view a copy of this license, visit http:// creativecommons.org/licenses/by-nc-nd/3.0/ 